\title{
GLOBAL VIEW
}

\section{Prevalence of and risk factors for hepatitis $C$ virus infection among STD clinic clientele in Miami, Florida}

\author{
J S Weisbord, M J Trepka, G Zhang, I P Smith, T Brewer
}

Sex Transm Infect 2003;79:el (http://www.sextransinf.com/cgi/content/full/79/1/e1)

See end of article for authors' affiliations

......................

Correspondence to: Joanna Weisbord, MSW $\mathrm{MPH}, 317$ Cardinal Medeiros Avenue,

Cambridge, MA 02141, USA; jweisbord@aol.com

Accepted for publication 4 October 2002

\begin{abstract}
Objectives: Hepatitis $\mathrm{C}$ virus $(\mathrm{HCV})$ is the most common chronic blood borne viral infection in the United States. We assessed the HCV prevalence, risk factors, and sensitivity of the Centers for Disease Control and Prevention's (CDC) routine screening criteria among clients of a large urban sexually transmitted disease (STD) clinic.

Methods: Participants were recruited from a public STD clinic in Miami, Florida, and were interviewed regarding known and potential risk factors. The survey assessed CDC screening criteria, as well as other risk factors (for example, intranasal drug use, history of incarceration, exchanging sex for money, number of lifetime sex partners, and history of an STD). Testing was done by enzyme immunoassay (EIA) and confirmed by recombinant immunoblot assay (RIBA).

Results: The prevalence of anti-HCV positivity was $4.7 \%$. Four variables were significantly associated with being anti-HCV positive, independent of confounding factors. These included injection drug use (odds ratio $(O R)=31.6 ; 95 \%$ confidence intervals $(C I) 11.0$ to 90.5$)$; history of incarceration $(\mathrm{OR}=$ $3.0 ; 95 \% \mathrm{Cl} 1.1$ to 8.1 ); sexual contact with an $\mathrm{HCV}$ positive person (OR 12.7; $95 \% \mathrm{Cl} 2.5$ to 64.7 ); and older age (OR $1.4 ; 95 \% \mathrm{Cl} 1.2,1.6)$. The sensitivity of $\mathrm{CDC}^{\prime}$ s routine screening criteria was $69 \%$ and specificity was $91 \%$.

Conclusions: The prevalence of anti-HCV in this clinic was similar to that determined in studies of comparable populations. Having sexual contact with an HCV positive person and history of incarceration were independently associated with being anti-HCV positive. CDC's screening criteria identified approximately two thirds of the anti-HCV positive participants.
\end{abstract}

$\mathrm{H}$ epatitis $\mathrm{C}$ virus (HCV) infection is the most common chronic blood borne infection in the United States. ${ }^{1}$ Although injection drug use and receipt of blood transfusions before 1992 are well documented risk factors, in approximately half of HCV cases, no identified percutaneous exposure exists. ${ }^{23}$ One study determined that HCV might be present in semen and vaginal secretions. ${ }^{4}$ In addition, studies have reported that HCV can be transmitted through sex, although inefficiently. ${ }^{4-6}$ Furthermore, studies of prostitutes, sex partners of HCV positive people, and people with a history of a sexually transmitted disease (STD) have documented higher rates of HCV infection among these populations than among the general population. ${ }^{78}$ Studies have examined transmission of HCV between monogamous partners or among people with high risk sexual behaviours. Although interspousal transmission has been documented, the risk for acquiring $\mathrm{HCV}$ is estimated to be low in a stable sexual relationship. $^{49}$ However, HCV might be more efficiently transmitted through sex in the presence of high risk sexual behaviours (for example, multiple sexual partners, unprotected sex) than among more stable, monogamous sexual partnerships. ${ }^{5710}$

One study among volunteer blood donors identified non-injection drug use, specifically intranasal drugs as a risk factor for $\mathrm{HCV}^{11}{ }^{11}$ However, the exact role non-injection drug use has in the transmission of HCV remains unclear, and the prevalence of HCV among this population is still unknown. ${ }^{23}$ Therefore, the Centers for Disease Control and Prevention (CDC) does not recommend routine testing of non-injection drug users. ${ }^{1}$ Outside the United States, HCV infection has been associated with tattooing and body piercing. ${ }^{12}{ }^{13}$ However, existing data from the United States do not indicate that people with exposure to tattooing and body piercing have an increased risk for HCV. Tattooing, body piercing, and injection of vitamins and medications outside the United States have been less extensively evaluated as potential risk factors for HCV. Because approximately half of Miami residents are foreign born, ${ }^{14}$ we hypothesised that therapeutic injection of vitamins, which is widespread in Latin America, would be more common among our study population than among the general US population.

CDC recommends routine HCV testing for anyone who

- ever injected illegal drugs

- was ever on long term haemodialysis

- has persistently abnormal aminotransferase levels

- was a recipient of blood transfusions or organ transplants before July 1992

- received clotting factor concentrates manufactured before 1987, or

- was notified that he or she received blood from a donor who later tested positive for HCV.

Post-exposure testing is also recommended for healthcare workers after a needle stick exposure to HCV infected blood, and for children born to an HCV infected woman.

The downtown STD clinic of the Miami-Dade County Health Department serves approximately $50 \%$ of all Miami's public STD clients. Since initiating HCV screening in the clinic, we have used CDC's criteria to determine who should be tested. However, the sensitivity of these screening guidelines among this STD clinic population is uncertain. The national estimated prevalence of HCV infection among people with a history of an STD is 6\% (range 1\%-10\%). ${ }^{1}$ We hypothesised that the prevalence of HCV infection among clients at this public STD clinic in Miami would be higher because of other potential risk factors (for example, a history of illegal intranasal drug use and injection drug use, exchange of sex for money, multiple sex partners, tattooing, body piercing, and injection of vitamins or medications while outside the United 
Table 1 Prevalence of antibody to hepatitis $\mathrm{C}$ virus (anti-HCV) by demographic and risk factors among sexually transmitted disease clients, Miami, Florida, January-March, 2001 ( $n=687$ )

\begin{tabular}{|c|c|c|c|c|}
\hline Characteristic & Total tested & Anti-HCV+ & Prevalence ratio & $\mathrm{p}$ Value \\
\hline \multicolumn{5}{|l|}{ Sex } \\
\hline Female & 282 & $12(4.3 \%)$ & 1.00 & \\
\hline Male & 405 & $20(4.9 \%)$ & 1.16 & 0.68 \\
\hline \multicolumn{5}{|l|}{ Age (years) } \\
\hline$<30$ & 293 & $6(2.0 \%)$ & & \\
\hline$\geqslant 30$ & 394 & $26(6.6 \%)$ & 3.26 & 0.005 \\
\hline \multicolumn{5}{|l|}{ Race/ethnicity } \\
\hline Non-Hispanic white & 43 & $7(16.3 \%)$ & 1.00 & \\
\hline Non-Hispanic black & 255 & $9(3.5 \%)$ & 0.21 & 0.003 \\
\hline Hispanic & 331 & $15(4.5 \%)$ & 0.28 & 0.007 \\
\hline Haitian & 53 & $1(1.9 \%)$ & 0.12 & 0.02 \\
\hline Non-Hispanic other & 5 & $0(0.0 \%)$ & & \\
\hline \multicolumn{5}{|l|}{ Education } \\
\hline$>$ High school & 206 & $9(4.4 \%)$ & 1.00 & \\
\hline High school & 240 & $9(3.8 \%)$ & 0.86 & 0.74 \\
\hline$<$ High school & 241 & $14(5.8 \%)$ & 1.33 & 0.49 \\
\hline \multicolumn{5}{|l|}{ US born } \\
\hline No & 382 & $14(3.7 \%)$ & & \\
\hline Yes & 305 & $18(5.9 \%)$ & 1.61 & 0.17 \\
\hline \multicolumn{5}{|l|}{ Blood transfusion } \\
\hline No* & 642 & $28(4.4 \%)$ & & \\
\hline Yes & 45 & $4(8.9 \%)$ & 2.04 & 0.15 \\
\hline \multicolumn{5}{|c|}{ Blood transfusion before 1992} \\
\hline No* & 651 & $28(4.3 \%)$ & & \\
\hline Yes & 36 & $4(11.1 \%)$ & 2.58 & 0.08 \\
\hline \multicolumn{5}{|l|}{ Injection drug use } \\
\hline No* & 661 & $17(2.6 \%)$ & & \\
\hline Yes & 26 & $15(57.7 \%)$ & 22.19 & $<0.0001$ \\
\hline \multicolumn{5}{|l|}{ Intranasal drug use } \\
\hline No & 522 & $16(3.1 \%)$ & & \\
\hline Yes & 165 & $16(9.7 \%)$ & 3.13 & 0.0004 \\
\hline \multicolumn{5}{|c|}{ Stuck with a needle with blood on it } \\
\hline No* & 673 & $26(3.9 \%)$ & & \\
\hline Yes & 14 & $6(42.9 \%)$ & 11.00 & $<0.0001$ \\
\hline \multicolumn{5}{|c|}{ Number of lifetime sex partners } \\
\hline$<50^{*}$ & 564 & $21(3.7 \%)$ & & \\
\hline$\geqslant 50$ & 123 & $11(8.9 \%)$ & 2.41 & 0.01 \\
\hline \multicolumn{5}{|l|}{ Diagnosed with STD } \\
\hline No* & 351 & $13(3.7 \%)$ & & \\
\hline Yes & 336 & $19(5.6 \%)$ & 1.51 & 0.23 \\
\hline \multicolumn{5}{|l|}{ Exchanged sex for money } \\
\hline No & 608 & $23(3.8 \%)$ & & \\
\hline Yes & 79 & $9(11.4 \%)$ & 3.00 & 0.01 \\
\hline Tattoo & & & & \\
\hline No & 489 & $23(4.7 \%)$ & & \\
\hline Yes & 198 & $9(4.6 \%)$ & 0.98 & 0.93 \\
\hline Body piercing & & & & \\
\hline No & 484 & $21(4.3 \%)$ & & \\
\hline Yes & 203 & 11 (5.4\%) & 1.26 & 0.54 \\
\hline Injected vitamins or mec & & & & \\
\hline No* & 673 & $31(4.6 \%)$ & & \\
\hline Yes & 14 & $1(7.1 \%)$ & 1.54 & 0.49 \\
\hline Injected vitamins or mec & & & & \\
\hline No* & 433 & $24(5.5 \%)$ & & \\
\hline Yes & 254 & $8(3.2 \%)$ & 0.58 & 0.15 \\
\hline History of prison or jail & & & & \\
\hline No & 417 & $7(1.7 \%)$ & & \\
\hline Yes & 270 & $25(9.3 \%)$ & 5.47 & $<0.0001$ \\
\hline Household contact with & & & & \\
\hline No* & 666 & $28(4.2 \%)$ & & \\
\hline Yes & 21 & $4(19 \%)$ & 4.52 & 0.01 \\
\hline Sexual contact with $\mathrm{HC}$ & & & & \\
\hline No* & 677 & $28(4.1 \%)$ & & \\
\hline Yes & 10 & $4(40.0 \%)$ & 9.76 & $<0.0001$ \\
\hline Ever been told HIV+ & & & & \\
\hline No* & 665 & $30(4.5 \%)$ & & \\
\hline Yes & 22 & $2(9.1 \%)$ & 2.02 & 0.28 \\
\hline
\end{tabular}

* "Don't know" responses were reclassified as "no."

The following were the number of "don't know" responses for each variable: Blood transfusion ( $n=12$ ); blood transfusion before 1992 ( $n=12$ ); injected drugs $(n=1)$; stuck with a needle with blood on it $(n=6)$; lifetime sexual partners $(n=2)$; diagnosed with an STD ( $n=1)$; injected vitamins or medications with used needles $(n=4)$; injected vitamins or medications outside United States $(n=13)$; household contact with HCV+ person $(n=181)$; sexual contact with $\mathrm{HCV}+$ person $(n=181)$; ever been told HIV+ $(n=11)$. 
States). The objectives of our study were to determine the prevalence of and risk factors for HCV infection among clients being examined at this STD clinic in Miami, Florida, and to determine the sensitivity and specificity of CDC's screening criteria among this population.

\section{METHODS}

Study participants were recruited from the downtown STD clinic of the Miami-Dade County Health Department, and included any client aged $\geqslant 18$ years who requested a clinical evaluation. Each participant gave informed consent, was interviewed by using a risk assessment questionnaire, and received counselling and education regarding hepatitis. The questionnaire assessed established risk factors for hepatitis $C$, as well as potential risk factors including tattooing, body piercing, injection of vitamins or medications while outside the United States, illegal intranasal drug use, exchange of sex for money, history of STDs, condom use, history of incarceration, length of incarceration, and human immunodeficiency virus (HIV) status. All study participants were assigned a unique identifying number to maintain their confidentiality. Institutional review board approval to conduct this study was obtained from the University of Miami, Florida Department of Health, and CDC.

After the interview, each client underwent venepuncture for viral hepatitis testing, which included antibody to hepatitis A virus, hepatitis B surface antigen, antibody to hepatitis B core antigen, antibody to hepatitis B surface antigen, and antibody to HCV (anti-HCV). An enzyme immunoassay (EIA) was performed to test for anti-HCV antibody, and confirmatory testing with recombinant immunoblot assay (RIBA) was performed on all samples with repeatedly reactive EIA results. Study participants were requested to return in 2 weeks to obtain their laboratory results. Data were analysed by using EPI-INFO $6{ }^{15}$ and SAS Software version 8.02. ${ }^{16}$ Univariate analysis was conducted with all known and suspected risk factors by using sas Software. Variables associated with HCV infection in the univariate analysis $(p \leqslant 0.1)$, were included in a logistic regression analysis. "Don't know" responses were grouped with "no" responses for sexual contact with an HCV infected person because those who replied "no" might not have known the HCV infection status of their partners. In addition, we excluded the one person who responded "don't know" to the question on injection drug use. Potential interactions between injection drug use and sexual contact with an HCV infected person, and having spent $\geqslant 1$ day in a prison or jail were assessed. Those factors that exhibited a statistically significant association $(\mathrm{p}<0.05)$ with being anti-HCV positive in the forward stepwise model were retained in the final model.

\section{RESULTS}

During January-March 2001, of the 1365 eligible clients 710 $(52 \%)$ were enrolled in the study. Reasons for refusing testing included time constraints, work commitments, and a belief of not being at risk for hepatitis. Of the 710 blood specimens collected, 23 (3\%) were insufficient for analysis, and the client did not return for a repeat phlebotomy. Therefore, analysis was conducted on 687 completed questionnaires and corresponding laboratory results; of these 32 (4.7\%) were anti-HCV positive.

Of the 687 participants, $59 \%$ were male, $48 \%$ were Hispanic, $37 \%$ were non-Hispanic black, $8 \%$ were Haitian, $6 \%$ were nonHispanic white, $1 \%$ identified their race/ethnicity as "other," and $56 \%$ were foreign born (table 1 ). The majority of participants had an education level of a high school diploma or less (70\%). The median age of the study population was 34 years (range 18-84). The median age of the anti-HCV negative participants was 31, compared with a median age of 45 for the anti-HCV positive participants. Being aged $\geqslant 30$ years and
Table 2 Results of multivariate logistic regression model examining associations between demographic and risk factors and antibody to hepatitis $C$ virus (anti-HCV) among sexually transmitted disease clients, Miami, Florida, January-March, 2001 ( $n=686$ )

\begin{tabular}{lll}
\hline Characteristic & $\begin{array}{l}\text { Adjusted } \\
\text { odds ratio }\end{array}$ & $95 \% \mathrm{Cl}$ \\
\hline Age $^{*}$ (per 5 years) & 1.4 & 1.2 to 1.6 \\
Injection drug use & 31.6 & 11.0 to 90.5 \\
History of incarceration & 3.0 & 1.1 to 8.1 \\
Sexual contact with HCV+ persont & 12.7 & 2.5 to 64.7
\end{tabular}

*Age was used as a continuous variable in the logistic regression model.

†"Don't know" responses classified as "no." The model did not change if "don't know" responses were excluded.

non-Hispanic white were the only demographic factors that were significantly associated with being anti-HCV positive in the univariate analysis (table 1 ).

In the univariate analysis, risk factors associated with antiHCV positivity $(\mathrm{p} \leqslant 0.1)$ included receiving a blood transfusion before 1992, injection drug use, illegal intranasal drug use, having been stuck with a needle with blood on it, having $\geqslant 50$ lifetime sexual partners, exchange of sex for money, having spent $\geqslant 1$ day in prison or jail, household contact with an HCV infected person, and sexual contact with an HCV infected person (table 1). Length of incarceration did not increase the risk for hepatitis C. Approximately half (48\%) of those participants who reported having a tattoo said the tattoo was done at an unconventional location (for example, home, prison, refugee camp, or on the street in a Latin American country). Approximately $35 \%$ of participants with body piercings also reported that they had them done at an unconventional location. However, neither tattooing nor body piercing, regardless of location, was associated with being anti-HCV positive in the univariate analysis.

In the multivariate analysis, four factors remained significantly and independently associated with anti-HCV positivity after accounting for other variables, and were retained in the final model. These included ever having injected drugs, having spent $\geqslant 1$ day in prison or jail, sexual contact with an HCV infected person, and older age (table 2). We found no statistically significant interaction between injection drug use and sexual contact with an HCV infected person. The strong correlation between injection drug use and having spent $\geqslant 1$ day in prison or jail precluded inclusion of an interaction term for these variables in the model (24/26 subjects who reported injection drug use, also had a history of having spent $\geqslant 1$ day in prison or jail). When "don't know" responses were excluded from the model, the same four factors had statistically significant associations with anti HCV positivity.

Twenty two $(69 \%)$ of the 32 anti-HCV positive people met one or more than one of CDC's routine screening criteria. The most commonly reported risk factor among the 22 cases who met CDC's screening criteria was injection drug use (68\%). Of the 10 anti-HCV positive people who did not meet any of CDC's screening criteria, three (30\%) reported injection of vitamins or medications while outside the United States; three $(30 \%)$ reported having spent $\geqslant 1$ day in prison or jail; and three $(30 \%)$ reported a history of illegal intranasal drug use and having spent $\geqslant 1$ day in prison or jail. The remaining antiHCV positive person reported injection of vitamins or drugs while outside the United States and having spent $\geqslant 1$ day in prison or jail. The sensitivity and specificity of CDC's screening criteria were $69 \%$ and $91 \%$, respectively. Adding a history of having spent $\geqslant 1$ day in prison or jail identified seven more anti-HCV positive cases and increased the sensitivity to $91 \%$, but decreased the specificity to $57 \%$. Forty per cent of the study participants had a history of having spent $\geqslant 1$ day in prison or 
jail. To identify these seven additional cases, 228 additional people would have to have been tested.

\section{DISCUSSION}

Previous studies that assessed the prevalence of HCV in STD clinics determined rates ranging from 3\% to $8 \% .{ }^{7{ }^{17}{ }^{18}}$ The $4.7 \%$ prevalence of HCV infection among the clientele at this public STD clinic in Miami falls within the range $(1 \%-10 \%)$ of prevalence for people reporting a history of an STD. We had hypothesised that the prevalence of HCV in this clinic would be higher than $6 \%$, considering other potential risk factors (for example, intranasal drug use, injection of vitamins or medications outside the United States, and tattooing in an unconventional setting) found among clinic attendees. However, these variables were not significantly associated with HCV infection in the analysis. Four of the anti-HCV positive clients reported a history of sexual contact with someone with hepatitis C, all of whom also reported a history of incarceration. Despite the limited number of people who reported sexual contact with an HCV infected person, we still found an independent association between this risk factor and being anti-HCV positive even after controlling for injection drug use and a history of incarceration.

Because of the questionable independent association between HCV infection and such factors as non-injection drug use and exchange of sex for money, we further assessed this relation among our STD clinic population. ${ }^{6}{ }^{71019}$ These factors were significantly associated with being anti-HCV positive in the univariate analysis, but none remained significant in the multivariate analysis. This could be because of the correlation between these behaviours and injection drug use. As suspected, a high proportion of our study population had received tattoos and body piercings at unregulated, unconventional locations (for example, refugee camps, prison, at home, or on the street in a Latin American country). Although this exposure has been suspected as a potential risk for spreading HCV, our findings did not support this association. In addition, injection of vitamins or medications while outside the United States did not increase the risk for HCV infection among our study population. It might be that the underlying prevalence of hepatitis $C$ in the areas where clients received the tattoos, body piercings, and injection of vitamins or medications, was low.

A key finding of this study is the association between incarceration and HCV infection, independent of injection drug use. This finding is consistent with studies conducted outside the United States that also determined that incarceration was associated with HCV seroconversion, and HCV infection was correlated with increased duration and number of incarcerations..$^{20-23}$ Although the opportunity for blood to blood contact through physical assaults and high risk sexual activity occurs in prison, the fact that length of incarceration did not increase the risk for HCV infection in our study indicates that this variable might be a marker for unreported injection drug use, another risk factor for HCV, or that the number of cases was too small to detect a dose-response relation.

The sensitivity of CDC's screening criteria among this study population was $69 \%$. Because a history of having spent $\geqslant 1$ day in prison or jail was independently associated with being anti-HCV positive, we added this variable to CDC's screening criteria and determined that it increased the sensitivity to $91 \%$. However, because such a high proportion of our STD clinic clientele reported a history of incarceration, to find each of the seven additional anti-HCV positive clients, we would have to screen approximately 30 additional people.

This study has certain limitations, including a low response rate $(52 \%)$. Reasons given for not participating included the client's belief that he or she was not at risk for the disease and time restraints. If the reason for declining to participate was truly a lack of time, time restraints would probably not vary on the basis of exposure or disease status, and would not result in selection bias. However, those clients who believed they were not at risk might have been more likely to be uninfected, resulting in a higher apparent HCV prevalence. Another limitation of the study was the fact that all risk factor data were self reported. Because many of the questions were sensitive, study participants might have under-reported certain socially unacceptable behaviours; this might have lead to an underestimate of the association between these variables and being anti-HCV positive. A third limitation is the lack of generalisability to a non-STD infected population. However, results from our study are probably generalisable to other urban STD clinic populations, especially those with a high percentage of foreign born clients of Hispanic and Caribbean descent, and those with a high percentage of clients who had a history of incarceration. A further limitation of the study was the number of participants who answered "don't know" to certain variables (for example, HIV status, their partner's HIV status, and whether they had had contact with an HCV infected person). However, that anti-HCV positive participants were more likely to respond "don't know" to these questions than anti-HCV negative participants is unlikely. A final limitation of this study was that at the time of interview, certain first time clients were still awaiting their STD test results and might have answered "no" to the question regarding STD diagnosis despite actually being infected with an STD. This might have resulted in an erroneously lower rate of clients reporting a history of an STD and contributed to a lack of association determined between being anti-HCV positive and having an STD.

Among this STD clinic population, we found a prevalence of HCV similar to that among other STD clinic populations. Although the sensitivity of CDC's routine screening criteria was not ideal among this population, the specificity was high; only $12 \%$ of the clinic population would need to be screened to identify almost $70 \%$ of the positives. If resources were available, however, we would consider evaluating the addition of a history of incarceration and sex with an HCV infected person to CDC's screening criteria used in this public STD clinic.

\section{ACKNOWLEDGEMENTS}

The authors thank Dolly Katz, Dave Culver, Sterling Whisenhunt, Maria Nuñez, Patrick Joseph, Shamista Dutta, Katiana Pierre, Anita Martinez, David McNeely, Jose Rossique, Jose Puerta, Maria Inez Oliveira, Gabriele Cohen, Ilsis Muñoz, and Pedro Móntes de Oca for their invaluable help with this study.

\section{CONTRIBUTORS}

JW, study methodology, design, implementation, data analysis, interpretation, manuscript writing; MJT, study methodology, design, implementation, data analysis, interpretation, manuscript writing, and editing; GZ, study methodology, sample size estimation, data analysis, interpretation; IP-S, study implementation, data analysis, interpretation, manuscript editing; TB, study design and methodology, implementation, manuscript editing.

\section{Authors' affiliations}

J S Weisbord, Centers for Disease Control and Prevention, Epidemiology Program Office, Public Health Prevention Service, Atlanta, GA, USA M J Trepka, G Zhang, I P Smith, Miami-Dade County Health Department, Office of Epidemiology and Disease Control, Miami, FL, USA

T Brewer, University of Miami School of Medicine, Department of Medicine, Miami, FL, USA

\section{REFERENCES}

1 Centers for Disease Control and Prevention. Recommendations for prevention and control of hepatitis $C$ virus (HCV) infection and $\mathrm{HCV}$ related chronic diseases. MMWR 1998;47(RR-19): 1-39.

2 Fiscus $\mathbf{S}$, Kelly WF, Battegelli DA, et al. Hepatitis C virus seroprevalence in clients of sexually transmitted disease clinics in North Carolina. Sex Transm Dis 1994;21:155-60. 
3 Alter MJ, Hadler SC, Judson FN, et al. Risk factors for acute non-A non-B hepatitis in the United States and association with hepatitis $C$ virus infection. JAMA 1990;264:2231-5.

4 Wejstal R. Sexual transmission of hepatitis $C$ virus. J Hepatol 1999:31(Suppl 1):92-5.

5 Thomas DL, Zenilman JM, Alter M, et al. Sexual transmission of hepatitis $C$ virus among clients attending sexually transmitted disease clinics in Baltimore-an analysis of 309 sex partnerships. J Infect Dis 1995;171:768-75

6 Nakashima K, Kashiwagi S, Hayashi J, et al. Sexual transmission of hepatitis $C$ virus among female prostitutes and clients with sexually transmitted diseases in Fukuoka, Kyushu, Japan. Am J Epidemiol 1992;136:1 132-7

7 Thomas DL, Cannon RO, Shapiro CN, et al. Hepatitis C, hepatitis B and human immunodeficiency virus infections among non-intravenous drug- using patients attending clinics for sexually transmitted diseases. J Infect Dis 1994;169:990-5.

8 Akahane $Y$, Kojima $M$, Sugai $Y$, et al. Hepatitis $C$ virus infection in spouses of clients with type $\mathrm{C}$ chronic liver disease. Ann Intern Med 1994; 120:748-52.

9 Serfaty L. Non-transfusional and non-intravenous drug addiction related transmission of hepatitis C virus. Presse Med 1999;28:1135-40.

10 Hershow R, Kalish L, Sha B, et al. Hepatitis C virus infection in Chicago women with or at risk for HIV infection; evidence for sexual transmission. Sex Transm Dis 1998:25:527-32.

11 Conry-Cantilena C, VanRaden M, Gibble J, et al. Routes of infection, viremia, and liver disease in blood donors found to have hepatitis $C$ virus infection. N Engl J Med 1996;334:1691-6.

12 Mele A, Corona R, Tosti ME, et al. Beauty treatments and risk of parenterally transmitted hepatitis; results from the hepatitis surveillance system in Italy. Scand J Infect Dis 1995;27:441-4.
13 Sun D-X, Zhang F-G, Geng Y-Q, et al. Hepatitis C transmission by cosmetic tattooing in women [Letter] Lancet 1996;347:541.

14 US Census Bureau. State and county quickfacts. Social characteristics; 1990, Dade County, FL. Available at http;//factfinder.census.gov (accessed 6 March 2002).

15 CDC Epi Info. [Computer program], version 6.0. Atlanta, GA; Centers for Disease Control and Prevention, 1994; available at http;//www.cdc.gov/epiinfo/

16 SAS Institute. SAS Software, version 8.02. Cary, NC, USA; SAS Institute Inc, 1999.

17 Gunn RA, Murray PJ, Ackers ML, et al. Screening for chronic hepatitis B and $C$ virus infections in an urban sexually transmitted disease clinic. Sex Transm Dis 2000;28:166-70.

18 Weinstock HS, Bolan G, Reingold AL, et al. Hepatitis C virus infection among clients attending a clinic for sexually transmitted diseases. JAMA 1993;269:392-4

19 Diaz T, Des Jarlais DC, Vlahov D, et al. Factors associated with prevalent hepatitis $C$; differences among young adult injection drug users in lower and upper Manhattan, New York City. Am J Public Health 2001;91:23-30

20 Anon $C$, del Olmo JA, Llovet $F$, et al. Hepatitis $C$ virus among the prison population of Valencia. Rev Esp Enferm Dig 1995;87:505-8

21 Haber PS, Parsons SJ, Harper SE, et al. Transmission of hepatitis C within Australian prisons. Med J Aust 1999;171:31-3

22 Butler TG, Dolan KA, Ferson M, et al. Hepatitis B and C in New South Wales prisons; prevalence and risk factors. Med J Aust 1997; 166:127-30.

23 Hedouin V, Gosset D. Infection with hepatitis C virus in a prison environment; a prospective study in Loos-lez-Lille, France. Gastroenterol Clin Biol 1998;22:55-8. 